\title{
1. The nature and evolution of econometrics
}

\subsection{ECONOMETRICS OR ECONOMIC-TRICKS?}

In the 1940s the term "econometrics" was a neologism (a new word), consisting of two Greek words: oikonomia (meaning administration or economics) and metron, which means measure (for example, Chait, 1949). In English, the literal meaning of "econometrics" is "economic measurement", although measurement may not appear explicitly as a function of econometrics. Today, econometrics is about more than measurement, and for the sceptics it is effectively "economy-tricks" (or "economic-tricks"), a collection of "tricks" used by economists to prove what they want to prove. Even econometrics enthusiasts refer to tricks in econometrics (for example, Varian, 2014). McAleer et al. (1985) start their paper by telling a story about a new typist for Carl Christ (a famous econometrician) who actually typed "econometrics" as "economic tricks" - for the sceptics the typist must have been observant and foresighted. For the time being, this cynical view of econometrics is put aside by considering what the discipline is all about from a historical perspective.

Although econometric techniques are widely used by both practitioners and academics, no generally accepted definition of econometrics exists - this is why Tintner (1953) referred to "the difficult problem of defining econometrics". To do that, he proceeded by giving a "preliminary definition", but the proper definition proposed by Tintner came only after presenting a definition of economics, identifying the forerunners of econometrics, defining quantitative economics (which presumably encompasses econometrics), and tracing the origin of the word "econometrics". Tintner suggested reasons as to why he preferred the definition of econometrics as a combination of economics, mathematics and statistics, which are the three pillars or components of econometrics as recognized universally. He argued that while the definition of econometrics was of some importance, it was to a certain extent arbitrary, but then he described econometrics as being related to economics in the same manner as psychometrics is related to psychology, sociometrics to sociology, and biometrics to biology. Typically, when it comes to defining econometrics, the tendency 
is to identify the sub-divisions (or branches) of the discipline, its pillars (or components), and the tasks (functions) that can be executed by using econometric techniques.

Econometrics has become a household term that can be found as an entry in the Collins Dictionary, where it is emphasized that the term is singular (www.collinsdictionary.com). The definition found in the Collins Dictionary is that econometrics is "the application of mathematical and statistical techniques to economic problems and theories". This brief definition overlaps with the definitions of related disciplines using quantitative techniques such as mathematical economics and operational research. However, it is typical that a description of what econometrics is all about gives rise to the problem of distinguishing econometrics from similar and close disciplines such as mathematical economics, statistics, economic statistics, mathematical statistics, statistical economics, quantitative economics, analytical economics, empirical economics, empirical econometrics, and perhaps operational research. The emphasis by the Collins Dictionary that the term "econometrics" is singular is due to the fact that many authors take the word to be the plural of "econometric". For example, Baltagi (2002) starts section 1.4 of his book by saying that "econometrics have experienced phenomenal growth in the past 50 years". I suppose that the word "econometric" is an adjective and adjectives have no plurals.

A large number of definitions can be found in the academic and professional literature - these definitions have common elements and they shed some light on the nature of econometrics. For example, the popular website Investopedia (www.investopedia.com) adopts the following definition of econometrics:

Econometrics is the application of statistical and mathematical theories to economics for the purpose of testing hypotheses and forecasting future trends. Econometrics takes economic models and tests them through statistical trials. The results are then compared and contrasted against real-life examples. Econometrics can be subdivided into two major categories: theoretical and applied.

Two characteristics of econometrics are embodied in this definition. The first is that econometrics consists of econometric methods (theoretical econometrics) and applied econometrics. Theoretical econometrics is about the development of estimation, testing and model evaluation procedures, whereas applied econometrics is about the application of econometric methods to economic issues. We will see later that econometric methods and applications evolved contemporaneously. The second characteristic is that econometric methods are designed to deal with either hypothesis 
testing or forecasting, although the two functions are related. This definition therefore identifies the branches of econometrics (methods and applications or theoretical and applied) and the functions that can be executed by using econometric techniques (hypothesis testing and forecasting). It is, however, not clear what is meant by "comparing and contrasting with reallife examples" - perhaps it means that when a model is used to generate forecasts, the predictive power of the model is assessed by comparing the forecasts with the corresponding actual (observed) data.

Another definition of econometrics, which can be found on lexicon. ft.com, is the following:

Econometrics is the art and science of using data to test various economic theories. More specifically, econometrics can be viewed as the use of mathematics and sophisticated statistical modelling to test economic or financial theories as well as forecast the effects of changes in economic or financial factors under various scenarios. . . Econometrics is an inter-disciplinary effort to understand economic and financial behaviour through the use of data, economic theory, mathematics, statistical methods, and other quantitative techniques.

This definition describes econometrics as art and science, but it does not tell us whether it is more like art or science. This is an important issue that will be examined later on when it is argued that neither econometrics nor economics is a science - at least not in the same sense as physics is a science. The definition also points to the main functions of hypothesis testing and forecasting and identifies the components of econometrics as economic theory, mathematics and statistics. However, the term "other quantitative techniques" may extend econometrics out of its natural boundaries. For example, some of the quantitative operational research techniques used to solve management problems include scheduling, transportation and network analysis. These techniques typically fall out of the realm of econometrics, which means that not all of quantitative techniques are used by econometricians. This is another issue that will be dealt with later.

\subsection{MORE DEFINITIONS}

Hansen (2011) contends that the best way to define econometrics is to go back to its roots, to the words of the "founding father", Ragnar Frisch (1895-1973), who was one of the three principal founders of the Econometric Society, the first editor of Econometrica, and a co-winner of the first Nobel Prize in economics in 1969. In an editorial of the first issue of Econometrica, Frisch (1933a) wrote the following: 
A word of explanation regarding the term econometrics may be in order. Its definition is implied in the statement of the scope of the [Econometric] Society, in Section I of the constitution, which reads: "The Econometric Society is an international society for the advancement of economic theory in its relation to statistics and mathematics. ... Its main object shall be to promote studies that aim at a unification of the theoretical-quantitative and the empiricalquantitative approach to economic problems.

This definition identifies the components of econometrics as economic theory, mathematics and statistics. However, Frisch argued that each of the three components was a necessary, but not by itself a sufficient condition for a real understanding of quantitative relations in modern economic life. Hence, he concluded that it was the unification of the three components that constituted econometrics. For Hansen (2011), "this definition remains valid today, although some terms have evolved somewhat in their usage". He goes on to define econometrics as "the unified study of economic models, mathematical statistics, and economic data", suggesting that the sub-divisions and specializations encompassed by econometrics are (1) econometric theory, which is about the development of tools and methods; and (2) applied econometrics, which is about the development of quantitative economic models and the application of econometric methods to these models using economic data. In his definition, Hansen adds data as a component of econometrics and lumps statistics and mathematics into one term, "mathematical statistics".

Several definitions come from recognized econometricians. For example, Haavelmo (1944) defined econometrics as a "conjunction of economic theory and actual measurements, using the theory and technique of statistical inference as a bridge pier". Samuelson, Koopmans and Stone (1954) stated that "econometrics may be defined as the quantitative analysis of actual economic phenomena based on the concurrent development of theory and observation, related by appropriate methods of inference". Spanos (1986) defined it as the systematic study of economic phenomena using observed data.

In a comprehensive survey of the discipline, Geweke et al. (2006) define econometrics more broadly by identifying its aims "to give empirical content to economic relations for testing economic theories, forecasting, decision making, and for ex post decision/policy evaluation". They also suggest that "econometrics calls for a unification of measurement and theory in economics", which is appealing because neither "theory" nor "measurement" on their own is sufficient to boost our understanding of how the economy works.

A detailed description of econometrics can be found in the International Encyclopaedia of the Social Sciences (www.encyclopedia.com), which describes econometrics in detail as follows: 
Succinctly defined, econometrics is the study of economic theory in its relations to statistics and mathematics. The essential premise is that economic theory lends itself to mathematical formulation, usually as a system of relationships which may include random variables. Economic observations are generally regarded as a sample drawn from a universe described by the theory. Using these observations and the methods of statistical inference, the econometrician tries to estimate the relationships that constitute the theory. Next, these estimates may be assessed in terms of their statistical properties and their capacity to predict further observations. The quality of the estimates and the nature of the prediction errors may in turn feed back into a revision of the very theory by which the observations were organized and on the basis of which the numerical characteristics of the universe postulated were inferred. Thus, there is a reciprocating relationship between the formulation of theory and empirical estimation and testing. The salient feature is the explicit use of mathematics and statistical inference. Nonmathematical theorizing and purely descriptive statistics are not part of econometrics.

This extended definition identifies the components of econometrics as economic theory, statistics and mathematics and recognizes the nature of observations (data) used for the purpose of estimating and testing economic functional relations. The definition (description) also identifies the "essential premise" that economic theory lends itself to mathematical formulation, which is not universally acceptable. Non-mathematical theory is excluded from econometrics, implying that mathematical economic theory (mathematical economics) is part of it. Also excluded are "purely descriptive statistics", presumably a reference to economic statistics. In this encyclopaedia entry, it is stated explicitly that "much of what is commonly known as econometrics is mathematical economic theory that stops short of empirical work" and that "some of what is known as econometrics is the statistical estimation of ad hoc relationships that have only a frail basis in economic theory". The implication of this definition is that the presentation of an economic theory by using diagrams and confronting it with observed data do not constitute econometric analysis. It is not clear if the implication of this description is that descriptive economic theory and economic statistics are not sophisticated enough, which makes it useless. A large number of econometricians and mathematical economists seem to think along these lines.

Perhaps the best way to understand what econometrics is all about is to describe it in terms of its branches (econometric methods and applied econometrics), functions (hypothesis testing and forecasting) and components (economic theory, mathematics and statistics). But even this description has significant overlapping with related disciplines as we are going to see later. The evolution of econometrics has led to a shift of emphasis in favour of econometric methods, as the development of new methods has 
become the end rather than the means to an end, and away from economic theory to pure mathematics and statistics. An Australian university is probably the only university in the world that has a separate department of econometrics, a department where the academics often brag about not using real data. If this is the case, where is measurement in econometrics?

\subsection{THE EARLY YEARS OF ECONOMETRICS}

Appendix Table 1A.1 displays a time line for the evolution of econometrics, going back to the works of Yule (1895) and Hooker (1901). While the term "econometrics" was used for the first time by Pawel Ciompa in 1910, it was Ragnar Frisch who established the discipline as we know it today (Bjerkholt, 1995). The precursor to econometrics was quantitative research in economics, the origins of which can be traced at least as far back as the work of the 16th-century political arithmeticians who analysed data in their studies of taxation, money and international trade. Geweke et al. (2006) suggest that two political arithmeticians (William Petty and Gregory King) presented the earliest unified quantitative/theoretical approach to economics. In the latter part of the 17th century William Petty published work on political arithmetic, which was econometric in its methodological framework even from the modern point of view.

Schumpeter (1954) argued that the "works of the political arithmeticians illustrate to perfection what Econometrics is and what Econometricians are trying to do". According to Charles Davenant (1698), Gregory King was the first to fit a linear function of changes in corn prices on deficiencies in the corn harvest, effectively estimating an excess demand function (for corn). Geweke et al. (2006) contend that the early empirical work of King and others "seems to have been the discovery of 'laws' in economics, very much like those in physics and other natural sciences". It will be argued later that there are no laws in economics and that the desire to make economics look like physics is probably due to inferiority complex on the part of economists going down that slippery slope. The proposition that there are laws in economics is ludicrous, to say the least (more about this in Chapters 3 and 4).

The use of mathematics in economics preceded the use of statistics - for example, in 1711 Giovanni Ceva, an Italian engineer, advocated the use of mathematics in economic theory. However, it was Leon Walras, the French economist credited for the formulation of the marginal theory of value and general equilibrium theory, who erected the foundations of modern mathematical economics. Although his work was removed from any immediate statistical application, he developed a comprehensive system of relations 
between economic variables (including money) in order to explain the mutual determination of prices and quantities of commodities and the capital goods produced and exchanged.

The birth of modern statistics in the late 19th century was pivotal for the emergence of econometrics, as econometric methods are essentially statistical methods modified to deal with economic relations. The earliest applications of simple correlation analysis in economics was carried out by Yule (1895) who examined the relation between pauperism (widespread and extreme poverty) and the method of providing relief, and by Hooker (1901) who investigated the relation between the marriage rate and the general level of prosperity. Henry Moore $(1914,1917)$ was the first to place the statistical estimation of economic relations at the centre of quantitative analysis in economics. Moore carried out econometric work on business cycles, the determination of wages, and the demand for certain commodities (see, for example, Stigler, 1962).

Moore's work was taken further by Schultz (1938), Allen and Bowley (1935), Wright (1915, 1928), Working (1927), Tinbergen (1930) and Frisch (1933b) who worked on the measurement of demand, family expenditure, and the problem of identification. Early empirical work in finance was carried out by Louis Bachelier (1900) who recognized the random walk character of stock prices, leading eventually to the emergence of the efficient market hypothesis as developed by Eugene Fama in the late 1960s and early 1970s. In macroeconomics, Clement Juglar (1819-1905) discovered the Juglar cycle, an investment cycle of about 7-11 years' duration, leading eventually to the work of Mitchell (1928) and Burns and Mitchell (1947) on the business cycle.

\subsection{SUBSEQUENT DEVELOPMENTS}

Econometrics as we know it today began to emerge in the 1930s and 1940s with the foundation of the Econometric Society and Cowles Commission. The Econometric Society was established to confront theoretical economics with reality and the advancement of economic theory in its relation to statistics and mathematics (Fisher, 1933). The Cowles Commission for Research in Economics was founded in Colorado Springs in 1932 by Alfred Cowles, a businessman and economist. In 1939 the Commission moved to the University of Chicago. In 1943 Jacob Marschak, who had left Oxford University to move to the US in 1939, became the director of the Cowles Commission, a post that he held until 1948 when he was succeeded by Tjalling Koopmans. Under Marschak's directorship, the Commission began an intensive study of the problems of estimation and 
identification associated with simultaneous equation systems. In 1948 Koopmans became the director of the Commission, playing an instrumental role in the development of work on the estimation of simultaneous equations. That work was published in three monographs: Statistical Inference in Dynamic Economic Models (edited by Koopmans, 1950), Economic Fluctuations in the United States, 1921-1941 (Klein, 1950), and Studies in Econometric Method (edited by Hood and Koopmans, 1953).

Rising opposition to the Cowles Commission by the Department of Economics at the University of Chicago during the 1950s encouraged the Cowles group to move to Yale University in 1955, where the Commission was reincarnated as the Cowles Foundation. The idea of the joint or simultaneous determination of certain economic variables was met with a degree of resistance from several parties, most notably from Wold (1949), who argued that multi-equation econometric models should be structured in a recursive manner, such that the inputs to each equation would be predetermined by preceding equations. In other words, the solution for the $n$th endogenous variable in a recursive system involves only the first $n$ equations. Wold rejected simultaneity, the notion that everything occurs at the same time on the grounds that the true description of economic events must be along a temporal sequence.

Initially, emphasis was placed on the development of econometric methods. It was the probabilistic rationalizations of regression analysis, advanced by Koopmans (1937) and Haavelmo (1944), that formed the basis of modern econometrics. Haavelmo (1944) defended the probability approach by arguing that the use of statistical measures (such as the mean, standard error and correlation coefficient) for inferential purposes is justified only if the process generating the data can be cast in terms of a probability model and that the probability approach is not suitable for the analysis of the dependent and non-homogeneous observations often encountered in economic research. Tinbergen (1937) saw the role of the econometrician as a passive one of estimating the parameters of an economic relation already specified on a priori grounds by an economist (although these days it is not clear who is an economist, who is an econometrician and who is both). Although he discussed the problems of the determination of time lags, trends, structural stability and the choice of functional forms, he did not propose any systematic methodology for dealing with them.

Keynes (1939) was critical of econometrics, mainly with respect to the technical difficulties associated with the application of statistical methods to economic data, emphasizing the problems of misspecification, multicollinearity, functional form, dynamic specification, structural stability, and the difficulties associated with the measurement of theoretical variables. In response to the criticism directed by Keynes at Tinbergen's work, 
Haavelmo (1943) recognized the need for a general statistical framework to deal with these criticisms, suggesting that the technical problems raised by Keynes could be dealt with by means of formal probabilistic models. Keynes was demonized by some econometricians for daring to criticize econometrics.

Geweke et al. (2006) recognize Haavelmo's contribution as marking "the beginning of a new era in econometrics", paving the way for the rapid development of the discipline. Specific developments cover the areas of (1) identification of structural parameters, (2) estimation and inference in simultaneous equation models, and (3) developments in time series econometrics. In the field of identification of structural parameters, important contributions were made by Koopmans, Rubin and Leipnik (1950), Wegge (1965) and Manski (1995). These contributions were about devising the rank and order conditions for the identification of a single equation in a system of simultaneous linear equations and structural parameters in the context of semiparametric models. Developments in applications or applied econometrics occurred simultaneously.

\subsection{MACROECONOMETRICS, MICROECONOMETRICS AND FINANCIAL ECONOMETRICS}

Significant changes took place in the global economic environment in the 1970s, arising largely from the breakdown of the Bretton Woods system and the quadrupling of oil prices - these developments had implications for the direction of research in econometric methods and applications. Mainstream macroeconometric models had been built and tested in the 1950s and 1960s, when economic stability prevailed under conditions of stable energy prices and fixed exchange rates. The prestige of large-scale macroeconometric models was damaged severely in the 1970s when it was revealed that their forecasting performance was often far inferior to that of the simple unconditional time series models of the autoregressive moving average (ARMA) variety, which were popularized in the 1970s by Box and Jenkins (1970). Pollock (2014) explains this observation by suggesting that, unlike ARMA models, the equations of the macroeconometric models did not address even the simple laws of linear dynamic systems.

In the 1970s and early 1980s, the Cowles Commission approach to the identification and estimation of simultaneous macroeconometric models was questioned by Lucas (1976), Lucas and Sargent (1981) and Sims (1980). The response to the Lucas critique has been to treat the structural change emphasized by Lucas as a potential econometric problem. 
There was also a move away from macroeconometric models towards microeconometric research. The emphasis gradually shifted from estimation and inference based on a given tightly parameterized specification to diagnostic testing, specification searches, model uncertainty, model validation, parameter variations, structural breaks, and to semiparametric and nonparametric estimation. These developments had an adverse effect on the role of economic theory as emphasis shifted to the invention of new econometric methods using advanced mathematical statistics.

The Lucas critique of mainstream macroeconometric modelling led some econometricians, notably Sims $(1980,1982)$, to be sceptical about the validity of the Cowles Commission style of achieving identification in econometric models. As an alternative, he suggested the use of a vector autoregressive (VAR) specification. In the "structural VAR" (SVAR) approach, it is assumed that structural shocks are orthogonal, but a mixture of short-run and long-run restrictions are used to identify the structural model. The focus of the SVAR literature has been on impulse response analysis and forecast error variance decomposition, with the aim of estimating the time profile of the effects of monetary policy, oil price or technology shocks on output and inflation.

Partly as a response to the dissatisfaction with macroeconometric time series research and partly in view of the increasing availability of micro data and computing facilities, interest shifted to the analysis of micro data. Important micro data sets have become available on households and firms in such areas as housing, transportation, labour markets and energy. These data sets include various longitudinal surveys (for example, the University of Michigan Panel Study of Income Dynamics and the Ohio State National Longitudinal Study Surveys), cross-sectional surveys of family expenditure, and population and labour force surveys. While opening up new possibilities for analysis, the increasing availability of micro data has also raised a number of new econometric issues primarily originating from the nature of the data. The models and issues considered in the microeconometric literature are wide ranging and include fixed and random effect panel data models (for example, Mundlak, 1961, 1978), logit and probit models and their multinominal extensions, discrete choice or quantal response models (Manski and McFadden, 1981), continuous time duration models (Heckman and Singer, 1984), and microeconometric models of count data (Hausman et al., 1984; Cameron and Trivedi, 1986).

Studies of the efficient market hypothesis (EMH) provided the impetus for the application of time series econometric methods in finance (hence the rise of the so-called financial econometrics). The EMH was built on the work of Bachelier (1900) and evolved in the 1960s from the random walk theory of asset prices advanced by Samuelson (1965). By the early 1970s 
a consensus had emerged among financial economists suggesting that stock prices could be well approximated by a random walk model and that changes in stock prices were basically unpredictable. Further developments in financial econometrics include equilibrium asset pricing models, modelling of asset return volatility (Engle, 1982, Bollerslev, 1986), analysis of high frequency intraday data, and market microstructure. Unfortunately, these developments have nothing to do with our ability to anticipate financial crises or devise a profitable trading strategy. As a matter of fact, work on the EMH in particular led to erroneous policies and the advent of the global financial crisis. We do not need financial econometrics to realize that greed-triggered fraud leads to financial mishaps. We do not need financial econometrics to find out that deregulation can bring about financial disasters. And we do not need financial econometrics to recognize the fact that bailing out (or bailing in) failed financial institutions under the pretext of too big to fail creates a moral hazard that perpetuates the occurrence of financial crises.

\subsection{RECENT DEVELOPMENTS}

Recent work in econometrics has been predominantly about the development of new estimation and testing methods without corresponding advances in empirical work on the working of the economy and financial system. In 1982 Robert Engle suggested the autoregressive conditional heteroscedasticity $(\mathrm{ARCH})$ model to represent volatility clustering, which opened the floodgates for a non-stop emergence of ARCH-like models. Bollerslev (2008) argues that what he calls "Rob Engle's seminal Nobel Prize winning 1982 Econometrica article" spurred a virtual "arms race" into the development of "new and better" procedures for modelling and forecasting time-varying financial market volatility. He contends that the output of this "industry" is a "perplexing alphabet-soup of acronyms and abbreviations used to describe the plethora of models and procedures that have been developed over the years". There have been more sequels to ARCH than to Jaws, Rocky, Rambo and Die Hard put together. As for "better" models, it is not obvious to me in what way the extensions and alternative are better - it has been an extravaganza that served no purpose whatsoever, apart from providing the means whereby students get their PhDs and academics get their promotions. What Bollerslev (2008) calls an "arms race" has been a total waste of brain power as we moved from ARCH to other versions of volatility models obtained by simple tweaks. The development of these models has dominated econometrics in the last 30 years or so, taking us from ARCH to its disciples as shown in Figure 1.1 


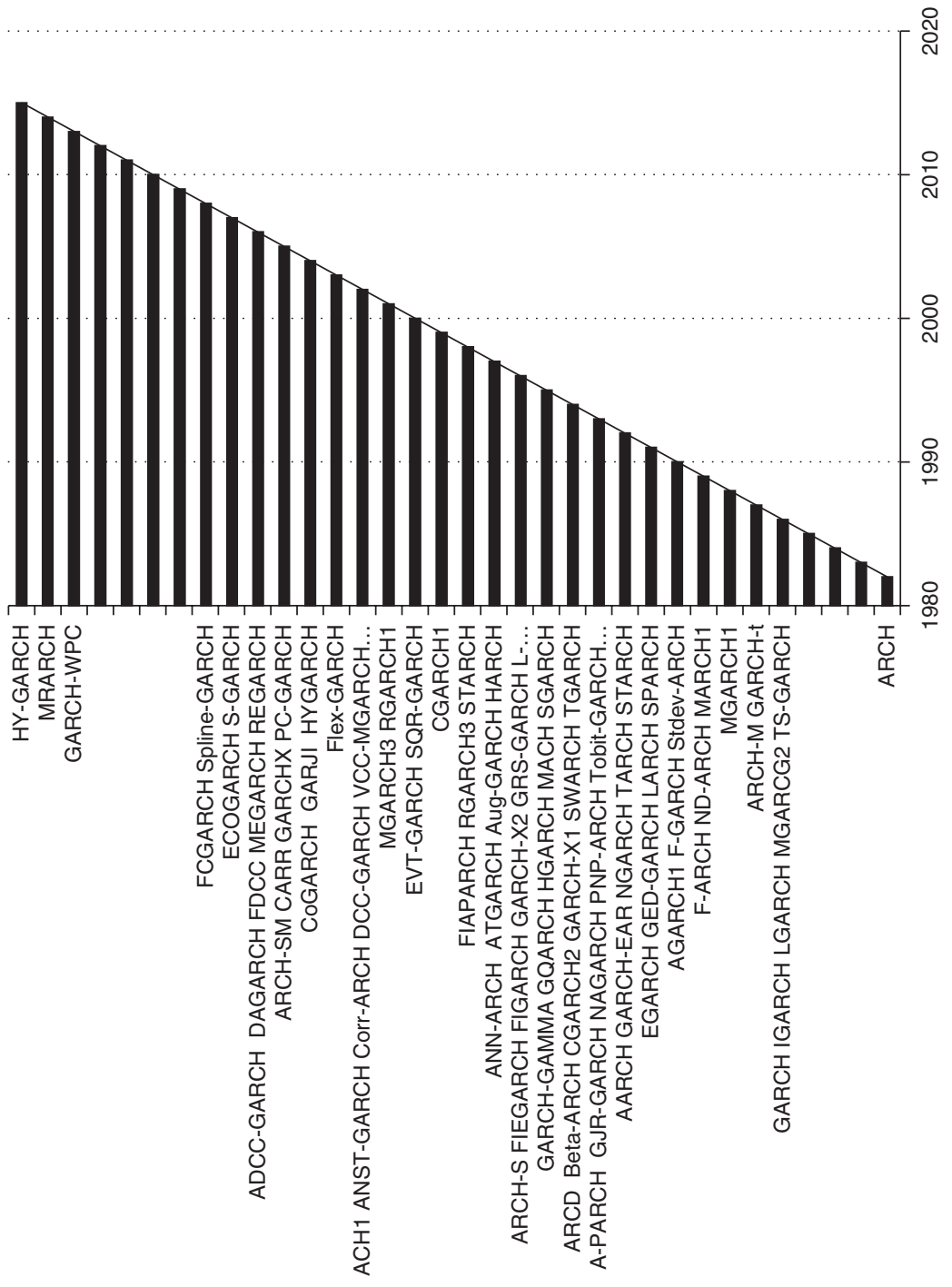

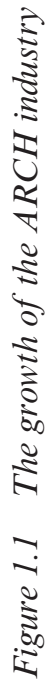


(which, by the way, does not represent an exhaustive list of $\mathrm{ARCH}$ models). It looks absolutely ridiculous, to say the least.

Extravaganza in estimation and testing methods continues - we used to have the instrumental variables method, now we have "jackknife instrumental variable estimation". Other new estimation methods include estimation with overidentifying inequality moment conditions, Bayesian estimation of dynamic discrete models, superparametric estimation of bivariate Tobit models, quantile regression for dynamic panel data with fixed effects, nonparametric instrumental regression, local GMM estimation, and many more. As for testing, recent developments include testing models of low-frequency variability, unit root quantile regression testing, specification tests of parametric dynamic conditional quantiles, and testing for common conditionally heteroscedastic factors. Even cointegration, which has proved to be a notion of dubious usefulness, has gone through some recent developments. In fact the Journal of Econometrics ran a special issue on cointegration in September 2010, dealing with topics such as likelihood testing for no fractional cointegration, which followed work on quantile cointegration regression and structural nonparametric cointegrating regression. All of these developments represent no more than extravaganza that has contributed nothing to our understanding of economics and finance.

\subsection{THE ALLEGED SUCCESS OF ECONOMETRICS}

Econometricians typically hail the evolution of econometrics as a "big success". For example, Geweke et al. (2006) argue that "econometrics has come a long way over a relatively short period". As indicators of the success of econometrics, they list the following: (1) applications of econometric methods can be found in almost every field of economics; (2) econometric models have been used extensively by government agencies, international organizations and commercial enterprises; (3) macroeconometric models of differing complexity and size have been constructed for almost every country in the world; and (4) both in theory and practice econometrics has already gone well beyond what its founders envisaged. Other measures of the success of econometrics include the observation that there is now scarcely a field of applied economics into which mathematical and statistical theory has not penetrated, including economic history. Pagan (1987) declares econometrics as an "outstanding success" because the work of econometric theorists has become "part of the process of economic investigation and the training of economists". Yet another indicator of the success 
of econometrics is the observation of excess demand for well-trained econometricians.

These claims represent no more than self-glorifying rhetoric, which at the limit considers the discovery or invention of ARCH to be as worthwhile of the Nobel Prize as the discovery or invention of Penicillin. The widespread use of econometrics is not indicative of success, just like the widespread use of drugs does not represent social success. Applications of econometric methods in almost every field of economics is not the same as saying that econometrics has enhanced our understanding of the underlying issues in every field of economics. It only shows that econometrics is no longer a means to an end but rather the end itself. The use of econometric models by government agencies has not led to improvement in policy making, as we move from one crisis to another. Constructing models for almost every country in the world has not helped alleviate poverty or solve recurring economic problems.

The observations that econometric theory has become part of the training of economists and that of excess demand for well-trained econometricians are far away from being measures of success. Including more and more statistical and mathematical material in curriculums amounts to squeezing out theoretical and applied courses (recall the concept of opportunity cost). While core microeconomics and macroeconomics courses remain, students do not have many electives left over to study things like labour economics, welfare economics, public economics, energy economics, case studies in economic policy, and so on. As a result of the alleged success of econometrics, courses in economic history and the history of economic thought have all but disappeared from the curriculum. The alleged success of econometrics has led to the production of economics graduates who may be good at number crunching but do not know much about various economic problems faced by humanity. How many universities in the world have a course in applied economics these days?

Doing sophisticated econometric work has nothing to do with the quest for the truth, but rather more with getting a paper accepted, which often involves confirmation bias. The use of econometrics and quantitative methods in general has become a minimum requirement to have a paper accepted in a highly-rated academic journal. According to Blommestein (2009), "this premium on quantification has had serious adverse consequences, including a misallocation of research efforts in economics". These days, a typical paper in economics follows a highly stylized structure involving the formulation of a theory in mathematical form followed by the construction of an empirical model, then comes the discussion of the empirical results. Whether or not these results contribute to our understanding of economic theory is a different matter - actually, it is totally irrelevant. 
The alleged success of econometrics has led to adverse consequences, starting with the brain drain inflicted on society by the movement of physicists, mathematicians and engineers to economics and finance, particularly looking for lucrative jobs in the financial sector. Instead of doing work to improve the fuel efficiency of the internal combustion engine, some innovative people originally working in science and technology have chosen to use their skills to indulge in the parasitic activity of developing new financial products and selling them as high-return, low-risk securities. At the same time, some good economists have left the field or retired early because they could not cope with the success of econometrics. On the other hand, good economists who do not do econometrics are looked down upon by the establishment. For example, Richard Posner, who is a non-believer in the efficient market hypothesis, made some sarcastic comments about the hypothesis in an interview with Cassidy (2010). When Cassidy interviewed Fama, the efficient market guru, he reacted rather furiously to Posner's comments, claiming that Posner is "not an economist" but rather "he's an expert on law and economics". This means that if your analysis does not involve "sophisticated quantitative work", you are not an economist, but if you hide behind equations you are a good economist. As a matter of fact, it is the brand of economics that Fama believes in (the physics-like economics) that has led to the mess we are in now. And it is the brand of economics that Posner believes in that will hopefully get us out of the mess.

Perhaps the success of econometrics can be measured by the increasing number of Nobel Prize winners awarded to econometricians for inventing ARCH, cointegration, causality, GMM, and various econometric methods. However, a Nobel Prize in economics (and peace for that matter) means nothing. Thompson et al. (2006) argue that the Nobel Prize has been awarded for nonsense, referring in particular to the Nobel Prize winning work in finance. Bergmann (1999) suggests that "we economists ought to open our eyes and see that having a Nobel Prize for economics is making the economics profession look ridiculous". She further refers to the embarrassment arising from the need to explain to the public the alleged achievement of the newest laureate. As examples, she mentions the prize won by economists telling us that "politicians and bureaucrats act in their own interest", that "people do the best they can in doping out what to do" and that "people save and spend their savings at different times in their lives". The Nobel Prize was even awarded to an economist who came up with the unethical conclusion that slavery was a good business, at least for those with the whip.

We must not forget that another Nobel Prize was awarded for the invention of that weapon of mass destruction, the efficient market hypothesis and other theories that are used to justify deregulation. Although the title 
of her article is "Abolish the Nobel for Economics", Bergmann suggests, as an alternative to abolishing the economics Nobel Prize, that the prize should not be awarded every year but rather only when work that advances economics as an empirical science appears. As long as neoclassical economics represents the mainstream, this is unlikely to happen because the research output will be about distilling complicated phenomena into simplistic representations of cheeringly optimal processes by using the available tools of econometric testing (Bergmann, 1999). Econometrics has not been a success because of the Nobel Prizes awarded to econometricians.

\subsection{THE MOVE TOWARDS ABSTRACTION}

Econometrics is no longer about measurement in economics as it has become too abstract. The meaning of the word "econometrics" is typically stretched to cover mathematical economics and the word "econometrician" refers to an economist, or otherwise, who is skilled and interested in the application of mathematics, be it mathematical statistics, game theory, topology or measure theory. Baltagi (2002) argues that research in economics and econometrics has been growing more and more abstract and highly mathematical without an application in sight or a motivation for practical use. In most cases, however, mathematization is unnecessary and a simple idea that can be represented by diagrams is made much more complex and beyond the comprehension of the average economist, let alone policy makers.

Heckman (2001) argues that econometrics is useful only if it helps economists conduct and interpret empirical research on economic data. Like Baltagi, Heckman warns that the gap between econometric theory and empirical practice has grown over the past two decades. Although he finds nothing wrong, and much potential value, in using methods and ideas from other fields to improve empirical work in economics, he does warn of the risks involved in uncritically adopting the methods and mindset of the statisticians. Econometric methods adapted from statistics are not useful in many research activities pursued by economists. A theorem-proof format is poorly suited for analysing economic data, which requires skills of synthesis, interpretation and empirical investigation. Command of statistical methods is only a part, and sometimes a very small part, of what is required to do useful empirical research.

The trend towards more abstract work can be seen in the contents of Econometrica. Table 1.1 lists the titles of selected articles from Econometrica in 1936, 1945, 1946, 2012, 2013 and 2016. In the 1930s and 1940s, Econometrica published papers on economics, dealing with microeconomic issues like the 
Table 1.1 The changing contents of Econometrica

\begin{tabular}{ll}
\hline Year & Title \\
\hline 1936 & Demand for Boots and Shoes as Affected by Price Levels and \\
& National Income \\
& Pareto's Sociology \\
& Vertical and Horizontal Shifts in Demand Curves \\
& Multiplier Effects of a Balanced Budget \\
& Measuring Marginal Utility by Reactions to Risk \\
& Liquidity Preference of Large Manufacturing Corporations \\
& (1921-1939) \\
& Theory of the Firm and Investment \\
& Capital Expansion, Rate of Growth and Employment \\
& Noisy Stochastic Games \\
& Reputational Bargaining with Minimal Knowledge of \\
& Rationality \\
& Mechanism Design with Renegotiation and Costly Message \\
& Timing and Self-Control \\
& Inference of Signs of Interaction Effects in Simultaneous \\
& Games with Incomplete Information \\
& Stability and Preference Alignment in Matching and Coalition \\
& Formation \\
& Definable and Contractible Contracts \\
& Efficiency in Games with Markovian Private Information \\
& Calibrated Incentive Contracts \\
& Discounted Stochastic games with No Stationary Nash \\
& Equilibrium \\
Reputational Bargaining and Deadlines \\
Robust Contracts in Continuous Time \\
Stochastic Learning Dynamics and Speed of Convergence in \\
Population Games
\end{tabular}

demand for boots and macroeconomic issues like the multiplier effect of a balanced budget. In recent volumes most of the papers are too abstract, use no data and do not provide new econometric methods that can be used in empirical work. Notice in particular the frequency of papers on game theory, which is supposed to be a branch of mathematics. Recent issues of Econometrica are dominated by what a frustrated academic economist once called "data-free mathematical masturbation", suggesting that it was not his "source of enlightenment" (Mason et al., 1992). This is why a joke goes as follows: during the rule of Nicolai Ceausescu in Romania, the government banned all "western" economics journals - the exception was Econometrica because it had nothing to do with economics. 
Another adverse consequence of the alleged success of econometrics is that we have become slaves, believing in its power and following blindly the implications of empirical results. When the results do not make sense, we do not reject them because common sense says so, we try to find an explanation for the results. For example, Moosa (2016a) has demonstrated that if we believe the results of empirical testing at the expense of common sense, we will believe that spending on science and technology leads to a higher rate of suicide and that the consumption of margarine is conducive to divorce. This has happened because of the dwindling role of economic theory in empirical work.

\subsection{ECONOMETRICS AS A TOOL TO PROVE ANYTHING}

Econometrics has been a success only in the limited sense that it can be used to prove almost anything. I have always challenged seminar presenters, saying that if they let me have their data I could turn their results upside down and come up with a different conclusion. Econometrics is very useful for those wanting to prove a pre-conceived belief or find results that support an ideologically driven hypothesis. Take, for example, Brexit, which had proponents and opponents. The empirical results produced by the opponents on the effect of Brexit on the British economy of leaving the $\mathrm{EU}$ are all over the place but ideological bias is conspicuous. For example, the Confederation of British Industry (2013), which is against Brexit, estimated the net benefit to Britain of EU membership to be in the region of 4 per cent to 5 per cent of GDP - that is, between $£ 62$ billion and $£ 78$ billion per year. Conversely, Congdon (2014) puts the cost of Britain's membership of the EU at 10 per cent, attributing this cost to regulation and resource misallocation. Congdon's estimates were prepared for the United Kingdom Independence Party (UKIP), which has a strong antiEurope stance.

Last, but not least, econometrics has been used to make outrageous claims and justify draconian economic policy. Econometrics has been used to justify inequality and defend the top 1 per cent. Econometrics has been used to justify tax cuts for the rich and support the trickle-down effect, which is no less than the rich pissing on the poor. Econometrics has been used to support the so-called "great moderation" and justify wholesale financial deregulation, the very policies that have led to growing poverty. When Ronald Reagan wanted to cut taxes for the rich, he hired the services of an economic outfit that produced results showing that cutting taxes for the rich would benefit the poor, which is a travesty in every sense of the 
word. George Bush Junior did the same, despite opposition from some high-calibre economists who argued that things did not work as envisaged by Bush and his advisers.

Econometrics has succeeded in one sense - it has succeeded as a con art, enabling anyone to prove anything. To be fair, econometrics has been a blessing, providing the means to get $\mathrm{PhDs}$ and academic promotions. This is what Richard Posner said in his comments on the efficient market hypothesis when he was interviewed by Cassidy (2010):

Well, one possibility is that they have learned nothing. . . because market correctives work very slowly in dealing with academic markets. Professors have tenure. They have lots of graduate students in the pipeline who need to get their Ph.D.s. They have techniques that they know and are comfortable with. It takes a great deal to drive them out of their accustomed way of doing business.

There is no wonder then that the likes of Richard Posner are not considered economists because they do not use econometrics. By the logic of this argument, neither Adam Smith nor John Maynard Keynes were economists because they did not use econometrics.

\subsection{CONCLUDING REMARKS}

We have been so obsessed with the success of econometrics that we even test the untestable. For example, numerous studies have been conducted to test covered interest parity, producing the usual mixed bag of results. When the results do not support CIP, those doing the research seek an explanation, thus producing a menu of why we observe deviations from CIP such as transaction costs, taxation, market imperfection, political risk, and so on. But the fact of the matter is that CIP is not a testable hypothesis. It is a definitional equation, an identity that represents the mechanism whereby bankers quote forward rates for their clients. Instead of testing CIP, an econometrician can ask a banker about the process whereby the forward rate is determined. The banker will tell him that it is calculated by adjusting the spot rate by a factor that reflects the interest rate differential, and that will be the end of the matter. But no, we have to "test, test and test", because econometrics is all about testing.

All it takes is to formulate a hypothesis, get data, test the hypothesis and generate forecasts. The more sophisticated it sounds the better it is. But in terms of advancing our knowledge of the working of the economy and financial markets, the contribution of econometrics has been zero at best and negative at worst. What have we learned about the working of financial markets by the progress made by moving from ARCH to GARCH and 
onwards to IGARCH, MGARCH, TS-GARCH, F-ARCH, AGARCH, LARCH, SPARCH, AARCH, QTARCH, STARCH, NAGARCH, PNP$\mathrm{ARCH}$, and so and so forth? Yes, econometrics has been quite a success, but only as a con art. 


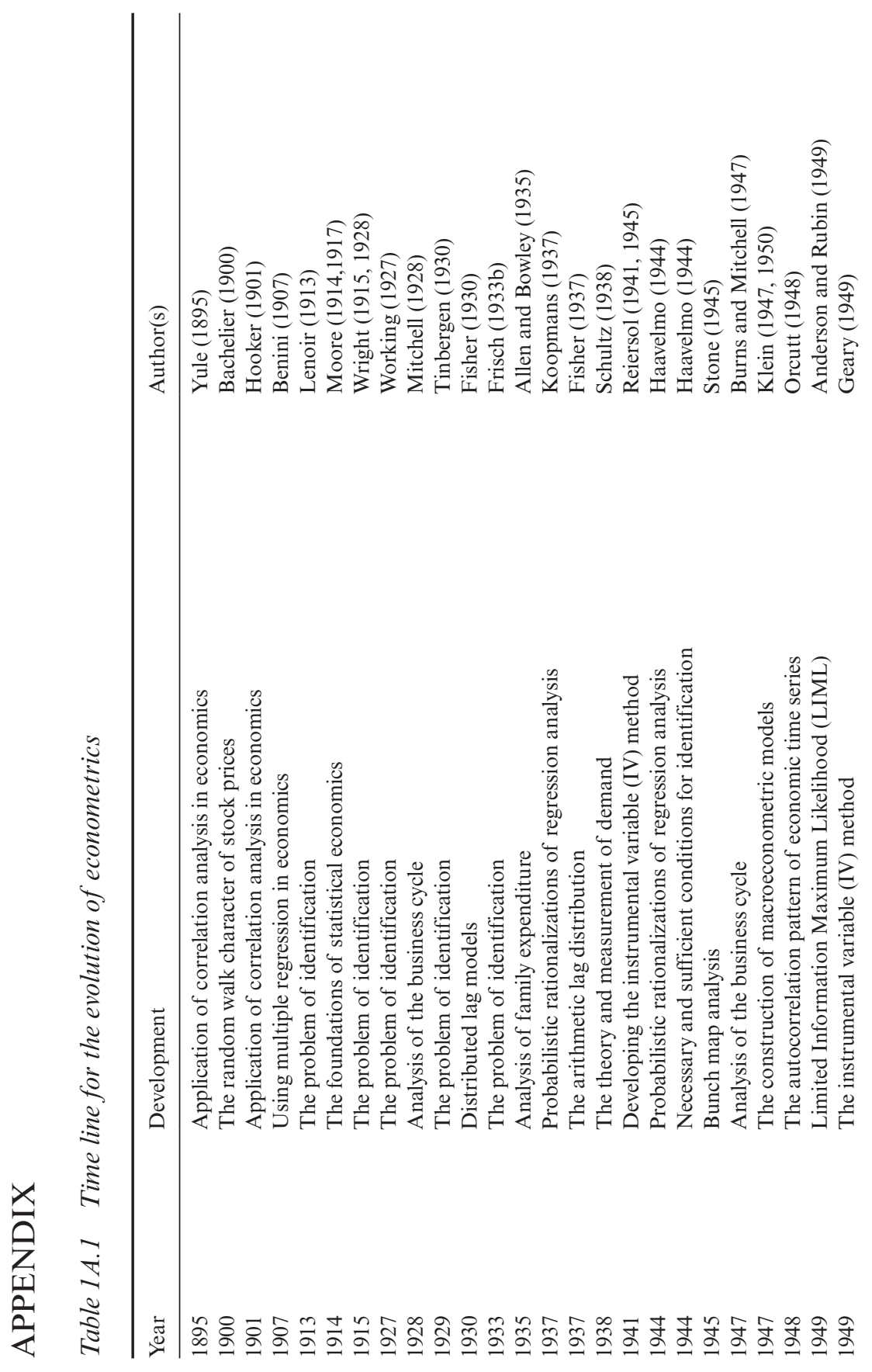




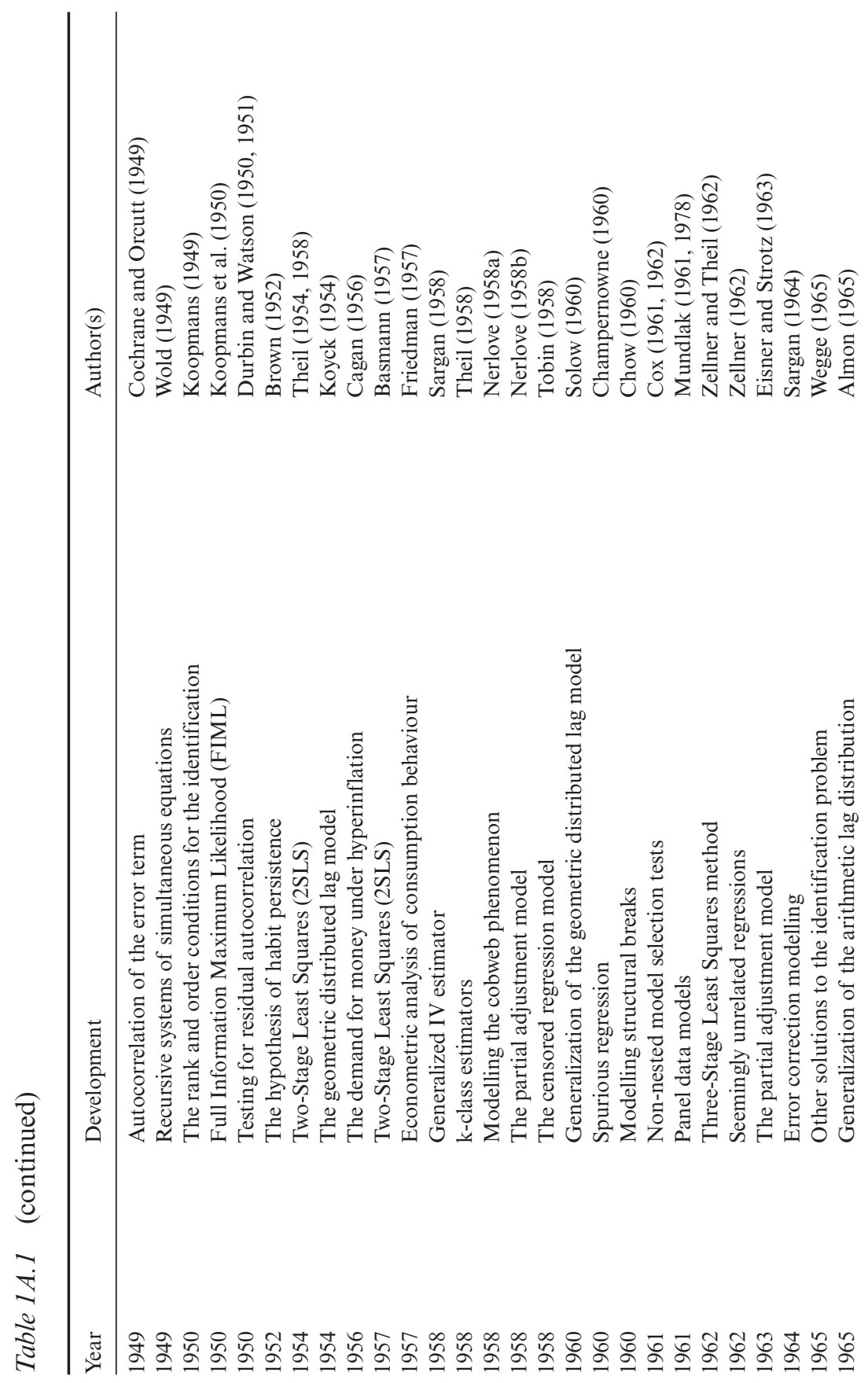



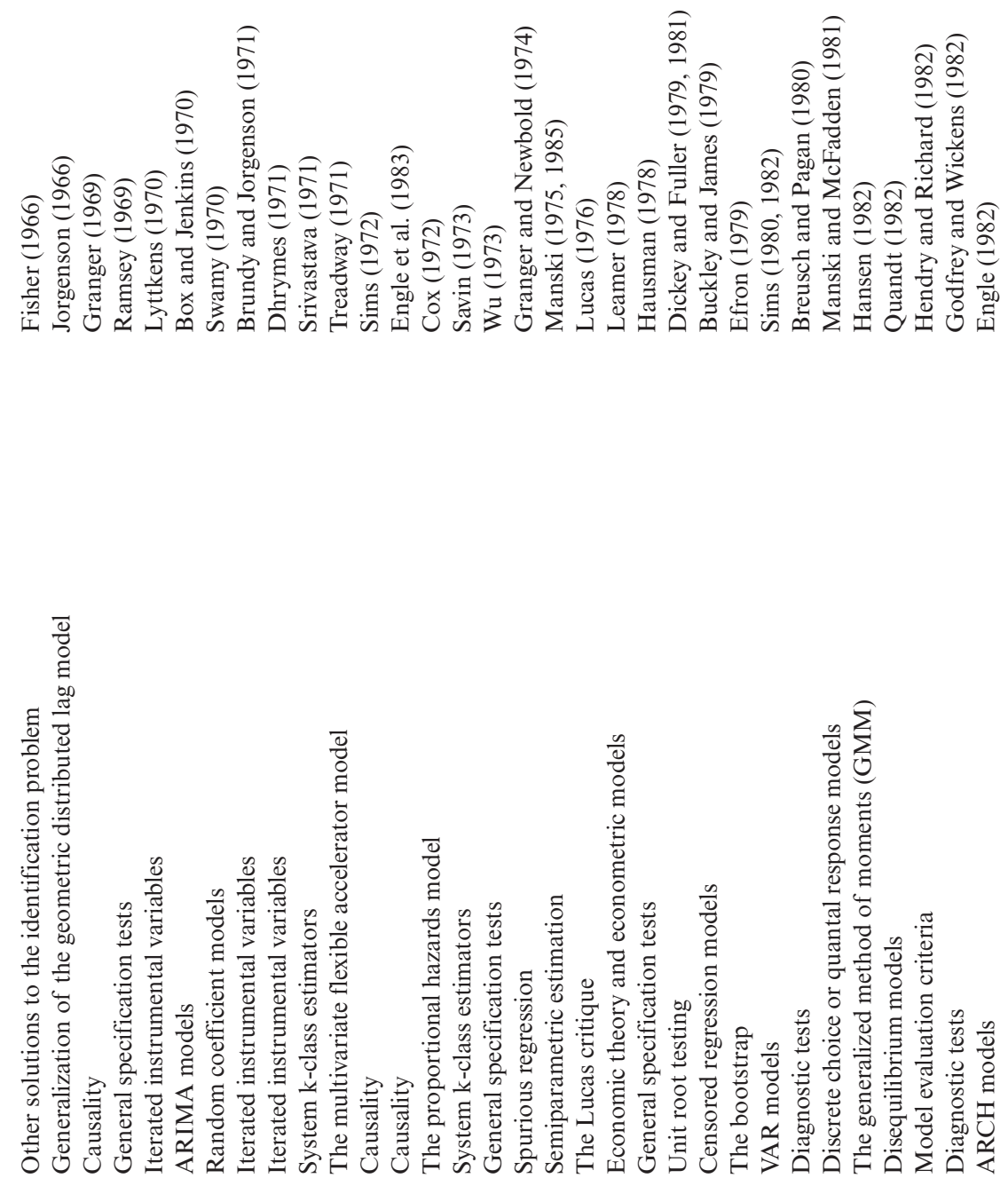

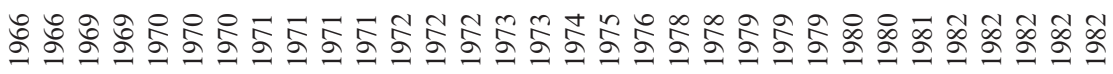




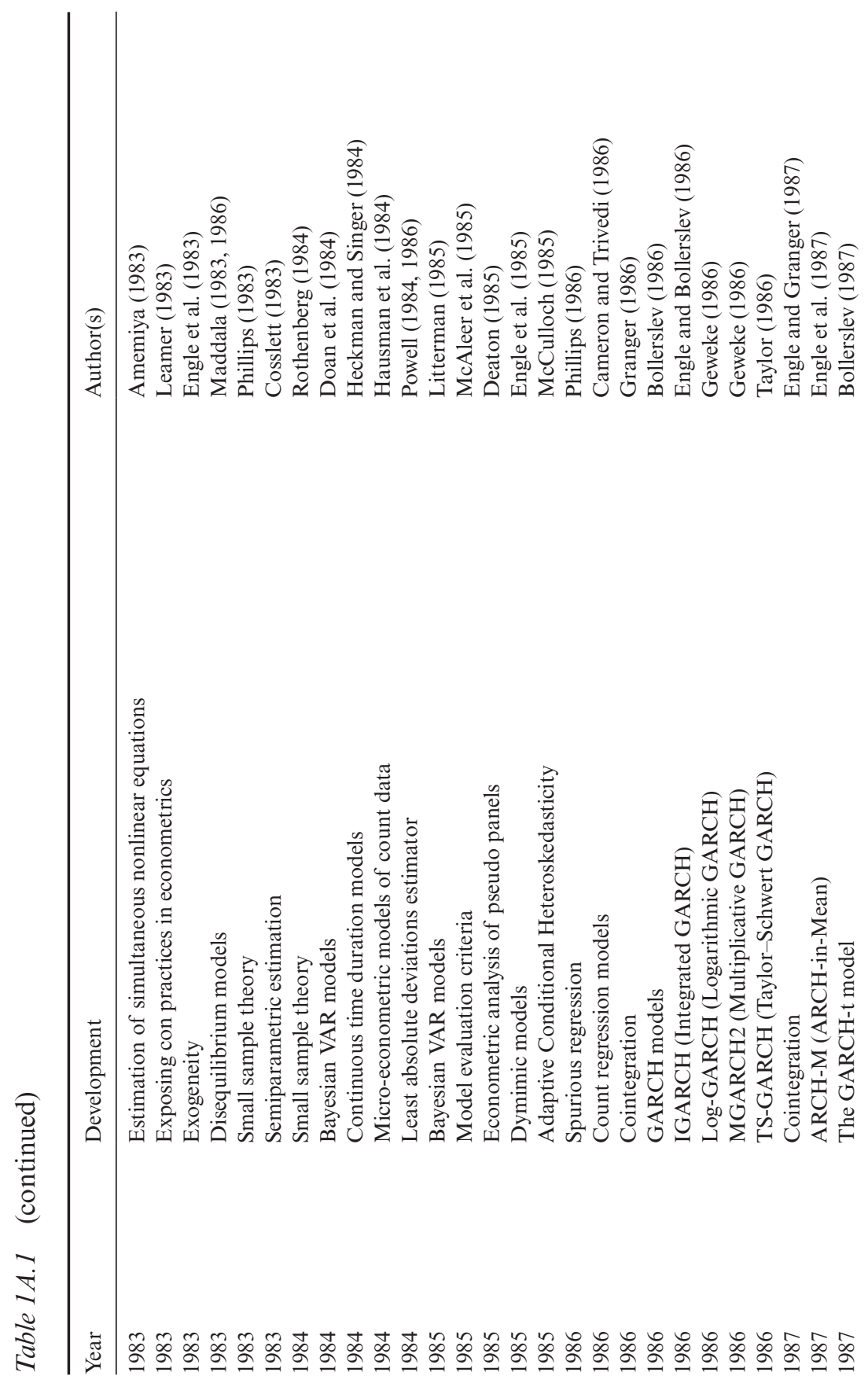



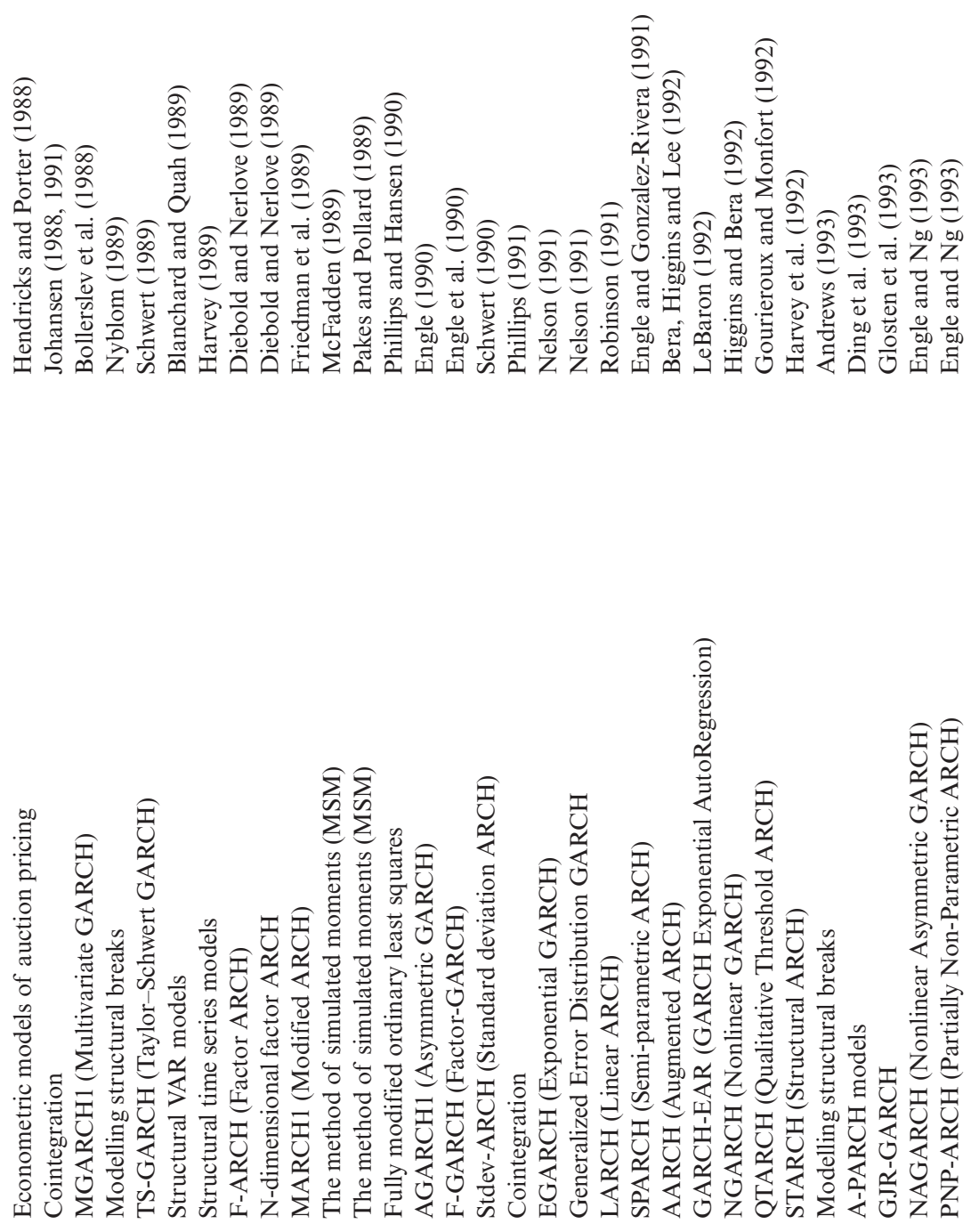

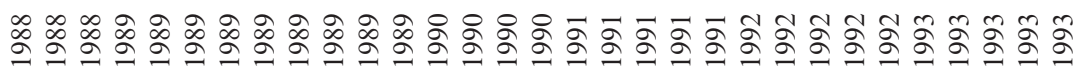




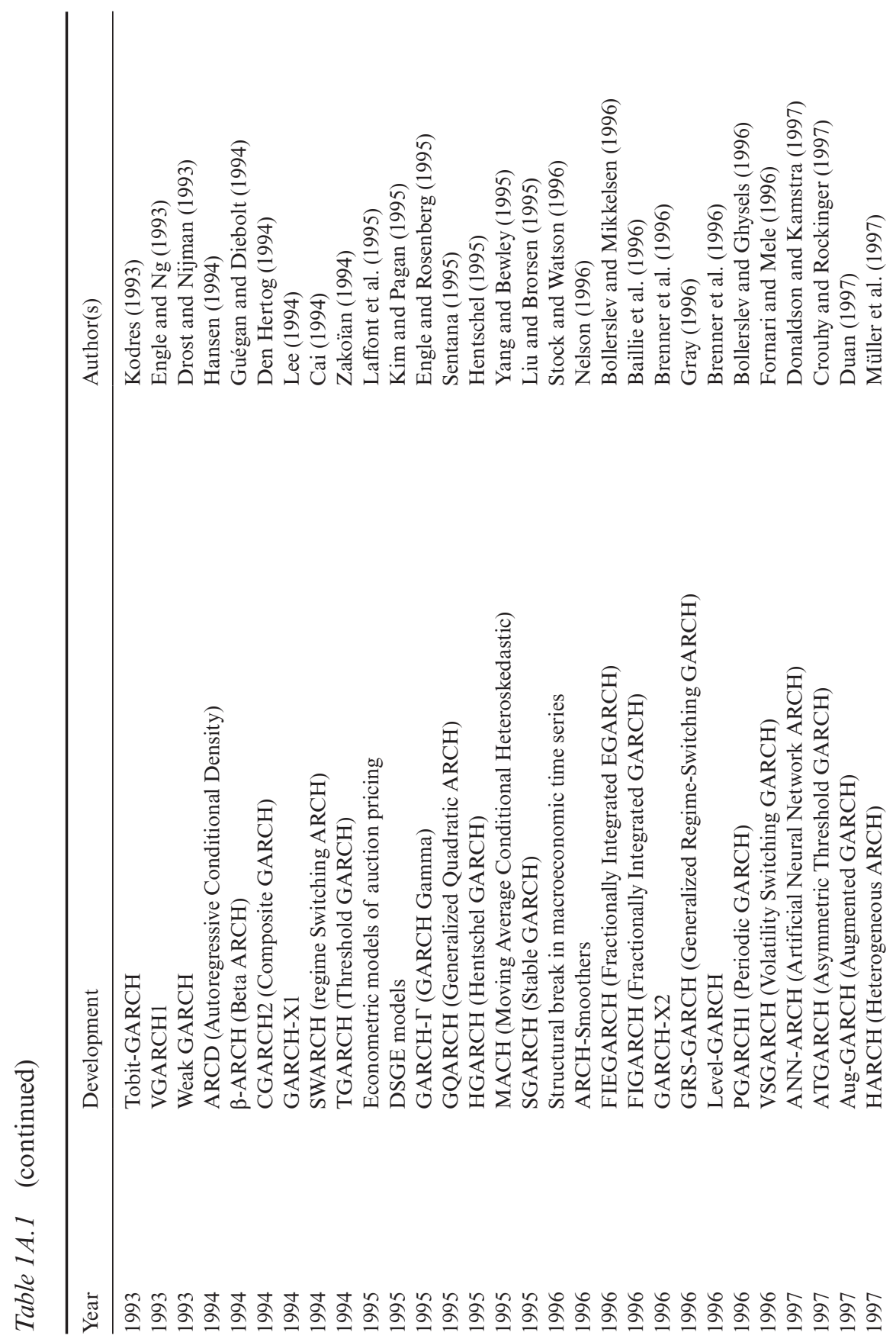



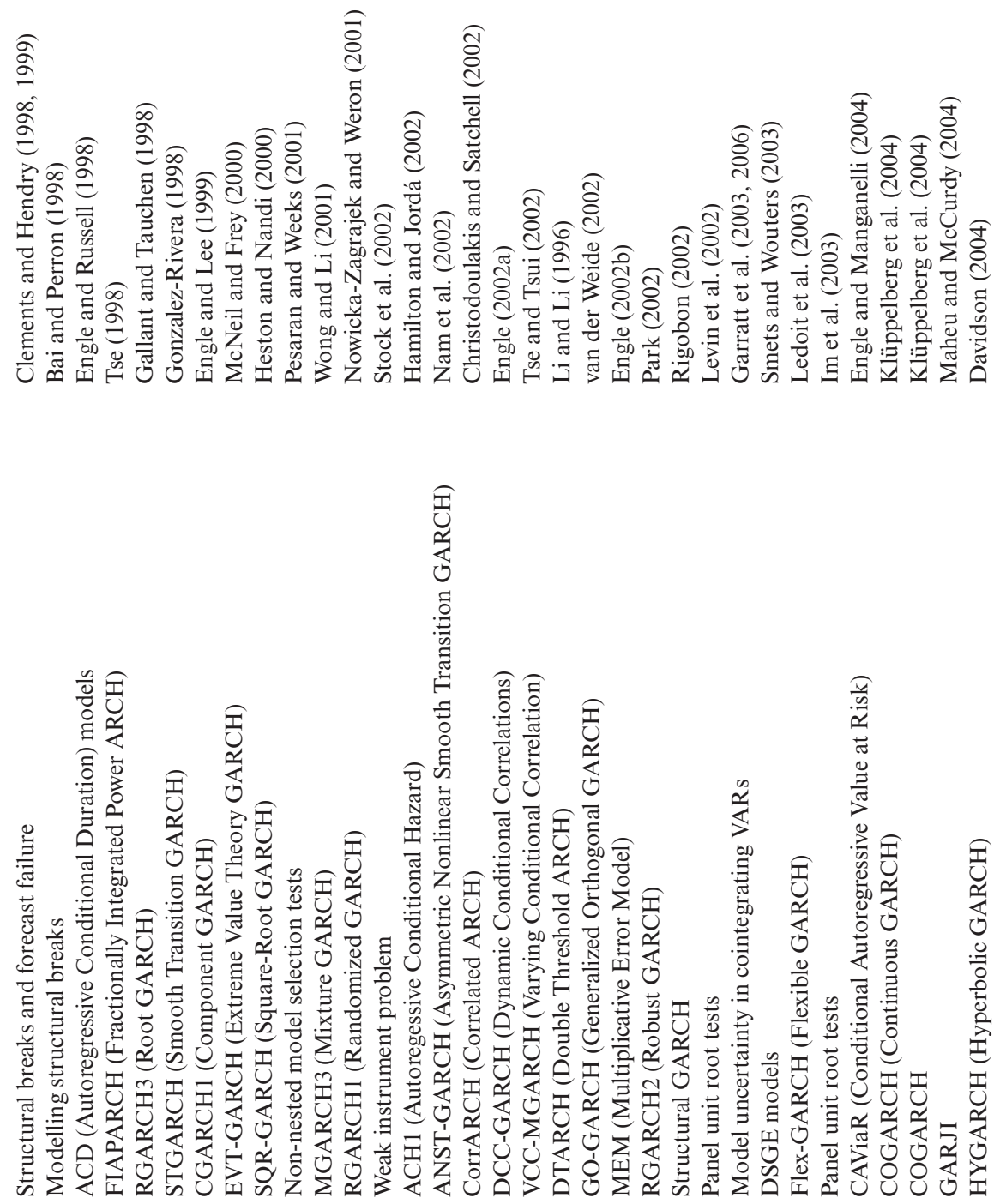

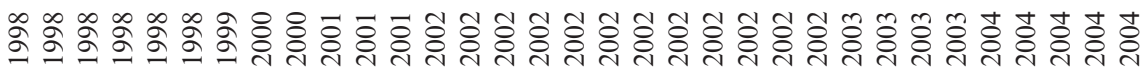




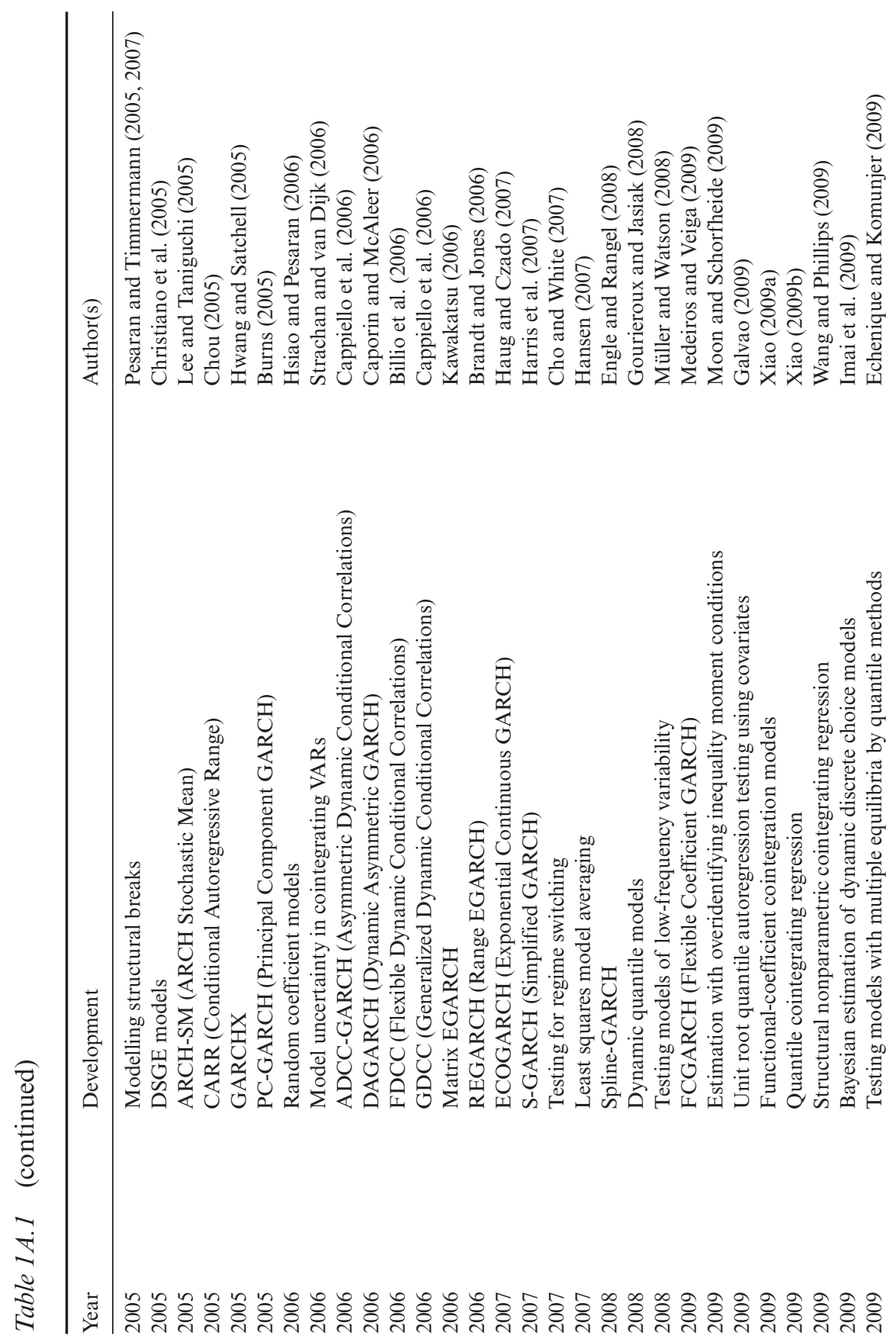



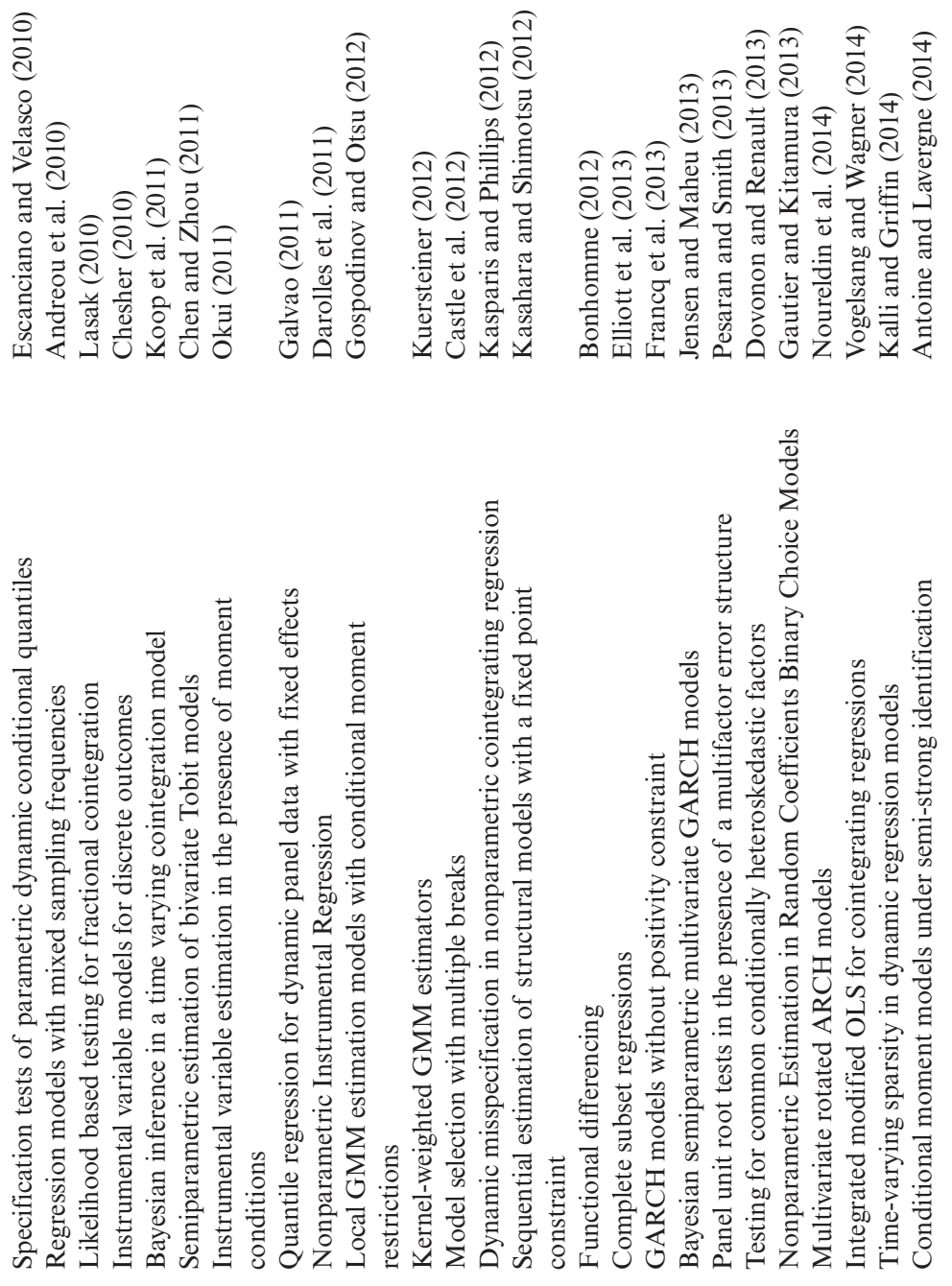

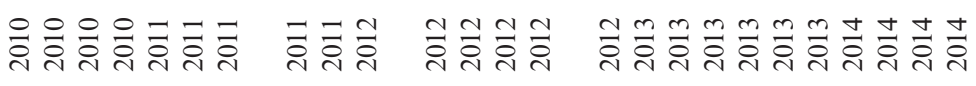




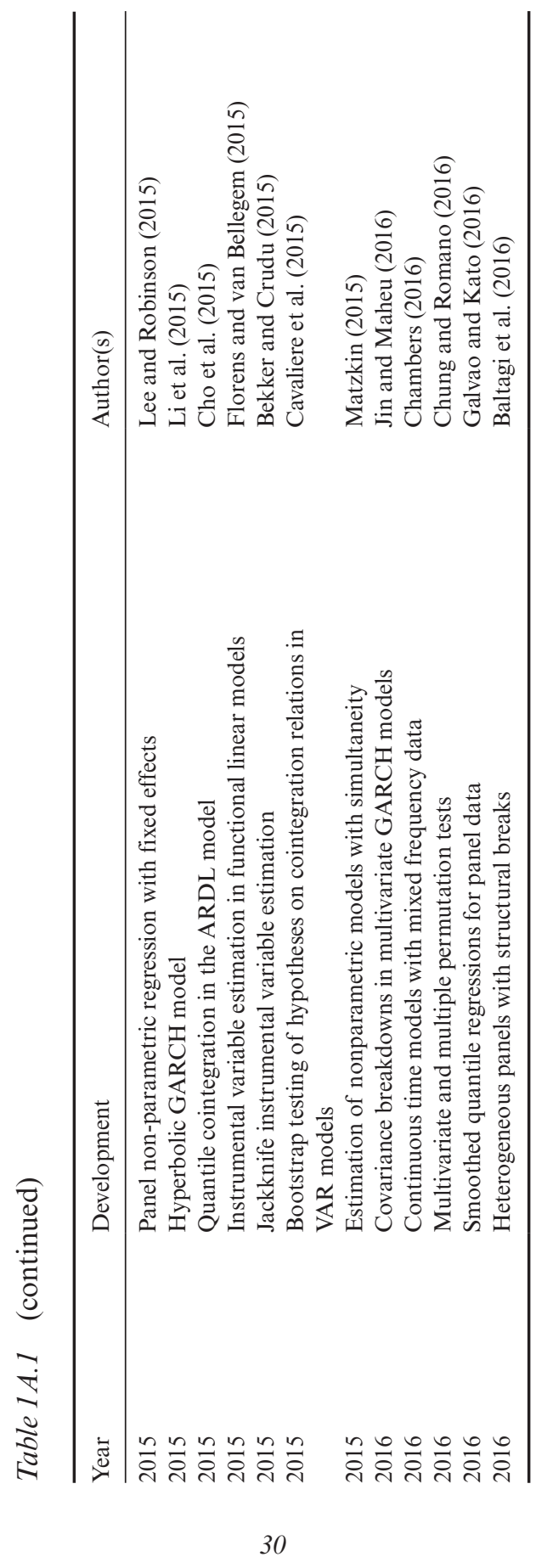

